\title{
A New Size Notation for Modern Books.
}

$T$ is an easy matter to criticise the various plans adopted for 1 marking in catalogues the sizes of books; it is less easy to suggest a more excellent way with any hope of its being so widely accepted as to become hereafter a recognised method. Nevertheless, so deplorable is the present lack of uniformity, and so certain is it that sooner or later the Library Association will have to take the matter in hand, that meanwhile it is pardonable if anyone who thinks he sees a simple and intelligible plan, suited to the needs of the rapidly increasing class of popular libraries, should advocate its adoption, or should at any rate submit it for consideration.

To remove at the outset certain obvious objections to a new and perhaps rough method, such as that which I am about to propose, I will say at once that $I$ have in view not the scientific accuracy of the learned book-lover, but the convenience of the general reader. To the former I leave the correct classification of all books printed before the close of the eighteenth century, confining my attention to those printed since the making of paper by machinery has become general. And although I seem thus to narrow my field unduly, I believe I shall still have to deal with nearly all the books in which a reader in one of our popular libraries is interested, and that nine-tenths, if not nineteen-twentieths of the contents of such libraries would fall to be classified under my scale.

It is unnecessary to argue before an audience of librarians that a new scale for marking the sizes of books is most desirable, assuming only that its common adoption can be secured. But I should be unable to do justice to my own proposal if I did not briefly point out some of the faults which it is designed to avoid. I do not come forward as an iconoclast. I confess to a certain affection for the time-honoured descriptions octavo, quarto and folio; nor do I suppose that under any circumstances they will altogether drop out of use ; but in order to avoid confusion. I do not employ them in the scheme I am about to propose. I might have included dicodecimo in my affectionate regards, were 
it not that it is in continual danger of being barbarously termed twelvemo; but for the rest, which rarely, if ever, are correctly read, but are familiar as sixteen mo, eighteen mo, twentyfour mo, thirty-two mo, and so on, ending with that which is popularly known as "post-one-hundred-and-twenty-eight mo" - surely these are an abomination, barbarous, misleading and useless.

And while there is this barbarism at one end of the scale, there is absurdity at the other. With us folio develops into royal, super-royal and imperial, while in America a large folio is styled an "elephant," though oddly enough, a larger still is termed an " atlas folio," (the same size that the French call an "atlantic folio"), and largest of all comes the "antiquarian folio"; whereas surely the average elephant is bigger than the average antiquarian, while the "atlantic" ought to be big enough to include them all. Again, in the middle of the scale we have the sub-divisions of octavo, not only into crown, demy, and royal, which are intelligible enough, but also into foolscap, post, pot, medium, super royal and imperial, while individual publishers add to the confusion by bringing in large crown octavo, globe octavo and others, until $\mathrm{Mr}$. Sothern, in his article in the Booknart, for October, 1885, estimates the total number of size-designations in actual use (though some of course are rare) at no fewer than two hundred.

This great elaboration and complexity would no doubt be pardonable if it secured strict accuracy ; but it is notorious that it does not. In many cases two skilled book-handlers (such a word we ought to have in English) would enter the same book under different size-designations. An American duodecimo, for example, overlaps an English octavo to the extent of nearly an inch. And the inaccuracy is not confined to size. The nomenclature in use, whether it be barbarous or not, is certainly misleading as applied to modern books. Originally of course it had to do with the folding of the paper, and only indirectly with the size of the page; and so long as paper was always hand-made, and was of certain recognised sizes, crown, demy, and royal being the most usual, the various foldings, which the water marks could always identify, produced the various sizes with tolerable accuracy. I do not say that even then all was simple and straightforward. One needs only to read through the Bodleian Library rules for distinguishing water-marked books (drawn up mainly, I believe, by Mr. William Blades, who in 
this department of bibliography as well as in others is a specialist second to none), to perceive that a technical education is requisite to qualify a man for this work. An acquaintance with the sizes of papers, ancient and modern, British and foreign, including the peculiarities of individual makers, is necessary if strict accuracy is desired. But at any rate the work when done has a real meaning and value-indeed in no other way can old books that have been cruelly cut down by successive binders be certainly identified as to their edition. But with the invention of paper-making by machinery all was changed. It was one thing when your paper was never more than 30 or 32 inches long by 22 inches wide; it is another when it may be a yard or two wide and as many miles long as you please. Calculation by folding is no longer a guide. Paper folded in duodecimo form may be equal to folio in size; and the result is that the old terminology, when used of modern books, is arbitrarily interpreted, not of the foldings but of the size and the size only, as being similar to that which the folding of the old hand-made paper used to produce.

This the Americans have done for some time past; but it is impossible to examine the method adopted by the American Library Association, and employed in the American Catalogue issued at the 'office of the Publishers' Weekly, without grave misgivings. The root-idea is to give the height in centimetres, beginning with ro and rising by $2 \frac{1}{2}$ to 20 , thence by 5 to 30 , and thence by 1o to 50,60 or 70 , where we meet with our friends the elephant, atlas and antiquarian folios rejoicing in the aliases of $F^{5}, F^{6}$ and $F^{7}$ respectively, by which we are to understand folios measuring 50,60 or 70 centimetres in height. Nor are the other verbal symbols or abbreviations less open to objection. If you are prepared to call a book about 4 inches high a quadragesimo octavo, or a $48 \mathrm{mo}$, surely it is better to mark it in figures, as we do, than to write $\mathrm{Fe}$; and similarly our method of writing sedecimo, duodecimo, octavo and quarto, is (I take it) to be preferred to the American S., D., O. and $Q$. This arbitrary system, though it has been in use for 13 years, is by no means universal in America, Caspar's Book Emporium using another scale based on inch measurements in place of centimetres (a method certainly more intelligible to the general reader) but also retaining the words implying fold-measurements, whereas size, and size only is taken into account.

I need not trouble you with any details about simplifications 
of the old-fashioned book-scale which English Librarians have suggested or have used. One of the best known is that which many of us have received, in the form of a 9 inch rule, from an enterprising Librarian in the north, Mr. Madeley, of Warrington. The only criticism that I will make on this, and on all similar scales, is that they are arbitrary in their employment of the old terminology; while the absence of any qualification for denoting the smaller octavo sizes, and the variability of the limit separating duodecimo from octavo, which is 7 inches in the Bodleian Library rules for indicating the sizes of books which are not identified by the water-mark;-i.e., I take it, of all modern books printed on machine-made paper- $7 \frac{1}{2}$ inches in Mr. Madeley's scale, and $7 \frac{7}{8}$ inches in the American scale. This I hold to be a very serious defect, as I will proceed shortly to explain.

Now when the average reader, whom I have throughout in view, consults the catalogue of his Public Library, what is there in regard to the size of the bnoks that it is important he should be able to ascertain? It does not matter to him the least in the world how the sheets of the book have been folded-presuming that is that the leaves have been cut-I mean cut in the sense of opened. Probably nearly every book in the library, large or small, has been folded in octavo form; but that is no concern of his. It is sufficient for his purpose if he can learn approxinately the size of the book that he proposes to take out or consult. And it is an adequate approximation if we recognise four sizes which we may distinguish as $A, B, C$ and $D$. The Greek letters $A, B, \Gamma$, and $\Delta$ have been suggested; but these might be less readily understood; while there is no fear of the others being confused with anything else, if printed in capitals and in special type. It is worth the readers' while to know if the book is quite a small one, such as can easily be slipped into the pocket, a book that some American librarians would class as minimo. And at the other end of the scale it is worth his while to know that the book is too big to hold in the hand-that a desk or table will be needed when he reads it. Between these two extremes the great majority of modern books will be found to lie; and it is important again to distinguish these into two classes, which I may designate the handy volume and the standard library volume respectively. We have now the four classes which I propose to mark A, B, C and D, and which a simple and easily-remembered inch scale will readily distinguish., 
A will include books less than 4 inches high; $B$ all books from 4 to 8 inches high; $C$ all books from 8 to 12 inches high; and $\mathrm{D}$ all books over $\mathrm{I} 2$ inches high. Perhaps when we get to the elephant, atlas and antiquarian folio-that is to books over 20 inches high-the big D ought to be doubled; but that is a matter of taste.

Now this division, simple as it is, secures the one distinction in the sizes of modern books which is really of importance when it is a question of identifying the edition-I mean the distinction between octavos, demy and under, which Mr. Madeley and the Bodleian rules throw together. The value of the distinction is obvious. Everyone knows that it is a common practice of publishers to issue a book first in demy octavo size, and then, when the edition is exhausted and a large sale seems assured, in a smaller, usually a crown octavo. And as these two editions very commonly differ considerably in the matter of corrections, of omissions or of additions, it is important that a reader consulting a catalogue should be able to tell which edition the library contains. But title-pages do not always specify the edition, and the date of the first issue is not always easily remembered. So that if either edition, in spite of the difference in size, is marked octavo in the catalogue, without any further qualification (as according to the rules I have referred to, it would be) the reader is left without any guide at all. Following however the method I am now proposing the original demy octavo edition would be marked $C$, and the latter smaller issue would be marked $\mathrm{B}$.

To conclude, then, what I claim for the A B C scale (as it may be termed) is this. It is as simple as anything of the kind can be, and it is easily remembered. It distinguishes the sizes of modern books sufficiently for the needs of the general reader. It does not profess to give information about the folding of the sheets, which the reader aforesaid really does not want to be troubled with; and, in making no such pretence, it avoids an obsolete or even barbarous phraseology, which has no business to be used to denote the sizes of modern books, since under the changed circumstances it no longer means what it says.

Of course I do not anticipate that my scale will be adopted by the British Museum, by the Bodleian, or by any other library containing great numbers of books printed before the end of the last century, which really require a more scientific classification. Nor do I suppose that the Library Association will 
see its way to any official approval of the plan. But I submit it to the librarians of popular libraries, whose number and importance increase every year, as a method which I believe they would find serviceable to themselves in lightening their labours, and serviceable to their readers in facilitating their reference to the books they wish to consult.

Arthur W. Hutton,

Librarian, Gladstone Library,

National Liberal Club. 